\title{
Portal vein reconstruction using side-to-side unification technique for infant-to-infant deceased donor whole liver transplantation
}

\author{
Jung-Man Namgoong ${ }^{1}$, Shin Hwang ${ }^{1}$, Chul-Soo Ahn ${ }^{1}$, Kyoung-Mo Kim², Seok-Hee $\mathrm{Oh}^{2}$, \\ Dae-Yeon Kim ${ }^{1}$, Tae-Yong $\mathrm{Ha}^{1}$, Gi-Won Song ${ }^{1}$, Dong-Hwan Jung ${ }^{1}$, and Gil-Chun Park ${ }^{1}$ \\ Departments of ${ }^{1}$ Surgery and ${ }^{2}$ Pediatrics, Asan Medical Center, \\ University of Ulsan College of Medicine, Seoul, Korea
}

\begin{abstract}
Backgrounds/Aims: Infant-to-infant whole liver transplantation (I2I-WLT) has been rarely performed in Korea. We analyze clinical sequences of our 7 cases of I2I-WLT and present evolution of surgical techniques to prevent PV stenosis. Methods: A total of 7 cases of I2I-WLT were performed at our institution during last 13 years, which represented $0.1 \%$ of our LT volume. Patient perioperative profiles and clinical sequences were analyzed with focusing on portal vein (PV) complications. Results: Donor ages were 6-17 months and graft weights were 140-525 g. Recipient ages were 7-16 months and body weights were 6-10.1 kg and Primary diagnoses were biliary atresia in 6 and progressive familial intrahepatic cholestasis in 1. The first case underwent PV stenting 2 months after I2I-WLT, and underwent retransplantation 6 years later. The second case underwent intraoperative PV stenting, but died 32 days later. The third case underwent repeated PV dilatation. The fourth, fifth and seventh cases experienced no surgical complications, and PV reconstruction was performed using a side-to-side unification venoplasty technique. The sixth case had poor development of the PV system, so customized PV venoplasty was performed, but PV occlusion requiring PV stenting occurred. Early retransplantation was performed, but scanty PV flow was detected despite no obvious PV stenosis, resulting in graft failure. Serious PV complications developed in 4, but none experienced after adoption of side-to-side unification venoplasty. Conclusions: As PV size in infant donors and recipients is very small, PV reconstruction in I2I-WLT requires specialized surgical techniques of side-to-side unification venoplasty. (Ann Hepatobiliary Pancreat Surg 2020;24:445-453)
\end{abstract}

Key Words: Complication; Portal vein; Pediatric transplantation; Deceased donor; Venoplasty

\section{INTRODUCTION}

Human individuals of any age can become organ donors after brain death occurs. Pediatric deceased donors, especially infant donors younger than 12 months old or with a body weight less than $10 \mathrm{~kg}$, can provide very smallsized solid organs. Considering graft-to-recipient size matching, the whole liver grafts from such infant deceased donors are the most suitable for infant recipients. The infant-to-infant whole liver transplantation (I2I-WLT) procedure has been rarely performed in Korea because of the extremely low incidence of infant deceased donors.

Thus, most of the liver transplantation (LT) procedures for infant recipients have been performed as a type of living donor LT (LDLT) or split LT. We have performed
6711 cases of LT, including 396 pediatric cases, prior to the end of $2019,{ }^{1,2}$ but we only experienced 7 cases of I2I-WLT out of 100 pediatric LT cases using split or whole deceased donor livers. Our experience with LDLT has provided valuable lessons that have allowed us to minimize the operative risk of pediatric LDLT, whereas the scarcity of I2I-WLT has led to a high incidence of major complications. Infant recipients with biliary atresia often exhibit PV hypoplasia with underdevelopment of the splanchnic blood flow system, and several innovative surgical techniques have been developed to prevent anastomotic stenosis of the PV. ${ }^{3-6}$ Unlike LDLT or split LT, the donor graft PV in I2I-WLT is very small in diameter, so the risk of PV complications increases significantly.

We herein present the clinical sequences of our 7 cases

Received: June 7, 2020; Revised: June 8, 2020; Accepted: June 29, 2020

Corresponding author: Shin Hwang

Department of Surgery, Asan Medical Center, University of Ulsan College of Medicine, 88 Olympic-ro 43-gil, Songpa-gu, Seoul 05505, Korea Tel: +82-2-3010-3930, Fax: +82-2-3010-6701, E-mail: shwang@amc.seoul.kr

Copyright (C) 2020 by The Korean Association of Hepato-Biliary-Pancreatic Surgery

This is an Open Access article distributed under the terms of the Creative Commons Attribution Non-Commercial License (http://creativecommons.org/ licenses/by-nc/4.0) which permits unrestricted non-commercial use, distribution, and reproduction in any medium, provided the original work is properly cited. Annals of Hepato-Biliary-Pancreatic Surgery - pISSN: 2508-5778 - elSSN: 2508-5859 
of I2I-WLT and discuss the evolution of surgical techniques to prevent PV stenosis.

\section{MATERIALS AND METHODS}

\section{Patients}

The LT database at our institution was searched to identify patients who underwent deceased donor whole LT during 13 years between January 2007 and December 2019. This study was focused on I2I-WLT, so the recipient criteria were individuals younger than 12 months old or with a body weight up to $10 \mathrm{~kg}$. Ultimately, we selected 7 cases of I2I-WLT from a total of 6711 LT cases. Medical records were reviewed retrospectively and the patients were followed up until December 2019.

\section{Surgical procedures}

The surgical procedures for I2I-WLT were quite similar to those used for adult recipients. Considering the extremely small size of the inferior vena cava (IVC), a piggy-back technique with double IVC anastomosis was used. ${ }^{7,8}$ For PV anastomosis, an end-to-end anastomosis using polypropylene (Prolene) interrupted sutures technique was used initially, but it was later changed to side-to-side unification venoplasty using polydioxanone (PDS) continuous sutures (Fig. 1). The hepatic artery was reconstructed under surgical microscopy. Biliary reconstruction was performed as Roux-en-Y choledocho-jejunostomy. Vascular inflow and outflow of the liver graft was assessed intraoperatively, immediately after abdomen closure, and daily during the first postoperative week.

\section{Development of side-to-side unification venoplasty technique}

After experiencing PV complications in the first three cases of I2I-WLT, we sought to develop a new surgical technique that would be suitable for I2I-WLT. For secure $\mathrm{PV}$ reconstruction, the effective size of the anastomotic cross-sectional area and a streamlined configuration without axial rotation are the essentially important parameters. ${ }^{3}$ We developed a computational simulation analysis to model the anastomosis of two small-caliber thin-walled tubes. The simulated technique was as follows: A deep longitudinal incision was made in the " 6 o'clock" direction of the graft PV and the "12 o'clock" direction of the recipi-

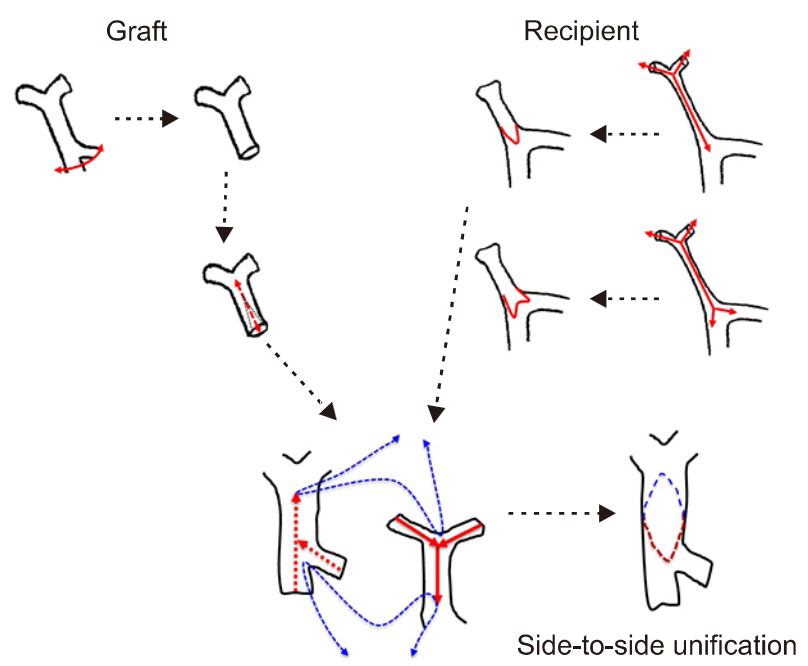

Fig. 1. Illustration of the side-to-side unification technique used for portal vein (PV) reconstruction. A deep longitudinal incision was made at the "6 o'clock" direction of the graft PV and the "12 o'clock" direction of the recipient PV. Running sutures were then used to unify these two PVs. This technique creates an enlarged conduit from the superior mesenteric vein-splenic vein confluence to the hilar PV confluence.

ent PV; then, continuous sutures were used to unify these two PVs, which generated an enlarged conduit from the superior mesenteric vein (SMV)-splenic vein (SV) confluence to the graft hilar PV confluence (Fig. 1). To evaluate the size of the anastomotic cross-sectional area and the contour of the anastomotic portion, we performed computational simulation analysis using computational fluid dynamics software (ADINA fluid-structure interaction model, ADINA R\&D, Inc., Watertown, MA). Thereafter, its technical feasibility was assessed by creating physical models with flexible heat-shrinkable polyolefin tubes. Vessel stenosis was induced by blowing hot air over the tubes, which were cut according to the shape obtained using the computational simulation model. Actual suturing was performed using this artificial vessel reconstruction model to confirm its technical feasibility.

\section{Approval of institutional review board and statistical analysis}

This study was performed in accordance with the ethical guidelines of the 1975 Declaration of Helsinki. The study protocol was approved by the institutional review board of Asan Medical Center (2019-0599).

Numerical data are presented as the mean and standard deviation. Survival curves were generated using the Kaplan- 
Meier method. Statistical analyses were performed using SPSS version 22 (IBM, New York, NY).

\section{RESULTS}

\section{Patient profiles and clinical outcomes.}

The mean recipient age was $10.1 \pm 3.0$ months (range: 7-16) and body weight was $7.2 \pm 1.7 \mathrm{~kg}$ (range: 6.0-10.1). Primary diagnoses of the recipients were biliary atresia in 6 cases $(85.7 \%)$ and progressive familial intrahepatic cholestasis in 1 case $(14.3 \%)$. The mean donor age was 12.0 \pm 4.3 months (range: 6-17). The mean weight of the whole liver grafts was $302.9 \pm 129.9 \mathrm{~g}$ (range: 140-525) and graft-recipient weight ratio (GRWR) was $4.13 \pm 1.30 \%$ (range: 2.7-6.0) (Table 1).

PV anastomotic stenosis occurred in 4 cases (57.1\%). Of them, one patients underwent percutaneous transhepatic angioplasty (PTA) and wall stent insertion and finally retransplantation was performed at 6 years of age (Case No. 1). Another patient underwent wall stent insertion at posttransplant day 1 and retransplantation at day 7 (Case No. 6). The other each one patient underwent intraoperative wall stenting (Case No. 2) and late PTA (Case No. 3).

PV complication developed in all three patients who underwent conventional end-to-end PV anastomosis (Case No. 1-3). In contrast, no PV complication developed after application of newly developed side-to-side unification

Table 1. Profiles of 7 cases of infant-to-infant whole liver transplantation

\begin{tabular}{|c|c|c|c|c|c|c|c|c|c|c|}
\hline $\begin{array}{l}\text { Case } \\
\text { No. }\end{array}$ & $\begin{array}{l}\text { Recipient } \\
\text { age } \\
\text { (months) }\end{array}$ & $\begin{array}{l}\text { Recipient } \\
\text { weight } \\
(\mathrm{kg})\end{array}$ & $\begin{array}{c}\text { Donor } \\
\text { age } \\
\text { (months) }\end{array}$ & $\begin{array}{l}\text { Graft } \\
\text { weight } \\
(\mathrm{kg})\end{array}$ & $\begin{array}{c}\text { GRWR } \\
(\%)\end{array}$ & $\begin{array}{l}\text { PV reconstruction } \\
\text { technique }\end{array}$ & $\begin{array}{l}\text { PV } \\
\text { complica- } \\
\text { tion }\end{array}$ & $\begin{array}{l}\text { PV } \\
\text { interven- } \\
\text { tion }\end{array}$ & $\begin{array}{l}\text { Retrans- } \\
\text { plantation }\end{array}$ & $\begin{array}{l}\text { Survival } \\
\text { outcome }\end{array}$ \\
\hline 1 & 10 & 6.5 & 9 & 220 & 3.4 & End-to-end & Yes & Stent & Yes & $\begin{array}{l}\text { Alive, } \\
>11 \text { years }\end{array}$ \\
\hline 2 & 7 & 6.8 & 12 & 265 & 3.9 & End-to-end & Yes & Stent & No & $\begin{array}{l}\text { Dead, } \\
32 \text { days }\end{array}$ \\
\hline 3 & 11 & 7.3 & 18 & 420 & 5.8 & End-to-end & Yes & PTA & No & $\begin{array}{l}\text { Alive, } \\
>6 \text { years }\end{array}$ \\
\hline 4 & 10 & 6 & 12 & 245 & 4.1 & Side-to-side & No & No & No & $\begin{array}{l}\text { Alive, } \\
>5 \text { years }\end{array}$ \\
\hline 5 & 16 & 10.1 & 17 & 305 & 3.0 & Side-to-side & No & No & No & $\begin{array}{l}\text { Alive, } \\
>5 \text { years }\end{array}$ \\
\hline 6 & 7 & 5.2 & 6 & 140 & 2.7 & $\begin{array}{l}\text { Modified } \\
\text { unification with } \\
\text { patch venoplasty }\end{array}$ & Yes & Stent & Yes & $\begin{array}{l}\text { Dead, } \\
37 \text { days }\end{array}$ \\
\hline 7 & 10 & 8.8 & 10 & 525 & 6.0 & Side-to-side & No & No & No & $\begin{array}{l}\text { Alive, } \\
>1 \text { year }\end{array}$ \\
\hline
\end{tabular}

GRWR, graft-recipient weight ratio; PV, portal vein; PTA, percutaneous transhepatic angioplasty
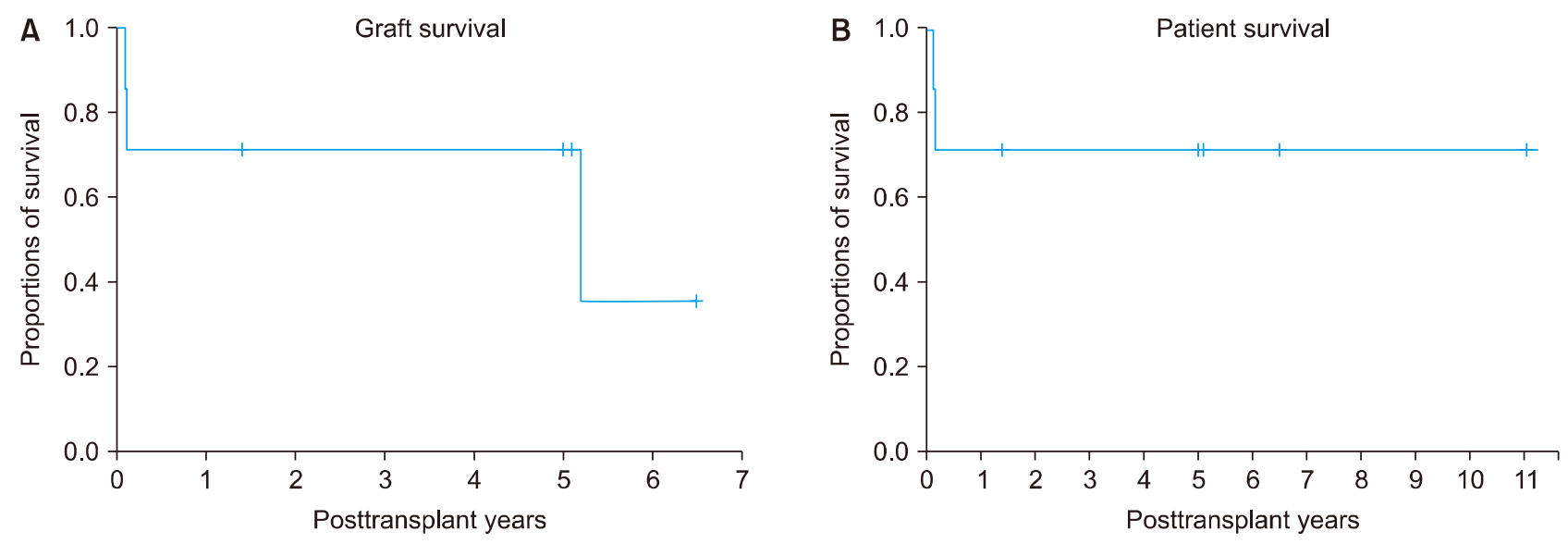

Fig. 2. Kaplan-Meier curves of the graft (A) and patient (B) survival. 
technique in all three patients (Case No. 4, 5, 7). However, one patient (Case No. 6) who received a modified technique of side-to-side unification combined with patch venoplasty underwent wall stent insertion and early retransplantation.

Two patients with PV complication died at posttransplant 32 days and 37 days and other five patients are alive for 2-12 years after transplantation. The graft and patient survival rates were $71.4 \%$ and $71.4 \%$ at 1 year, $71.4 \%$ and $71.4 \%$ at 3 years, and $47.6 \%$ and $77.4 \%$ at 6 years, respectively (Fig. 2).

\section{Detailed case presentation}

Case No. 1: The recipient was a 10-month-old female baby who weighed $6.5 \mathrm{~kg}$. She was diagnosed with biliary atresia. The deceased donor was a 9-month-old girl. The total graft weight was $220 \mathrm{~g}$, and the GRWR was $3.4 \%$. The PV was reconstructed using end-to-end anastomosis. At postoperative day 2, serum aspartate transaminase (AST) and alanine transaminase (ALT) levels increased to 1752 IU/L and 1433 IU/L, respectively. A dynamic computed tomography (CT) scan revealed multiple infarcts of the liver graft that primarily resulted from liver compression within the small-sized abdominal cavity. Serial imaging studies revealed the presence of PV anastomotic stenosis, so balloon dilatation was performed and a wall stent was inserted at posttransplant 2 months. Her liver function progressively deteriorated and eventually she underwent re-transplantation with a split liver graft when she was at 6 years of age. She is currently doing well and is 12 years old (Fig. 3).

Case No. 2: The recipient was a 7-month-old female baby with weight of $6.8 \mathrm{~kg}$. She had undergone Kasai operation for biliary atresia. The deceased donor was a 12-month-old boy. The graft weight was $265 \mathrm{~g}$, so the GRWR was $3.9 \%$. The PV was underdeveloped, but end-to-end anastomosis was performed. Because of weak PV flow, she underwent intraoperative PV stenting. At postoperative day 2, serum AST and ALT levels increased to $8751 \mathrm{IU} / \mathrm{L}$ and $2918 \mathrm{IU} / \mathrm{L}$, respectively. A dynamic CT scan revealed decreased perfusion of the liver parenchyma. Her liver function progressively deteriorated and ultimately she passed away 32 days after LT (Fig. 4).

Case No. 3: The recipient was an 11-month-old female baby who weighed $7.3 \mathrm{~kg}$. She had undergone Kasai operation for biliary atresia. The deceased donor was an
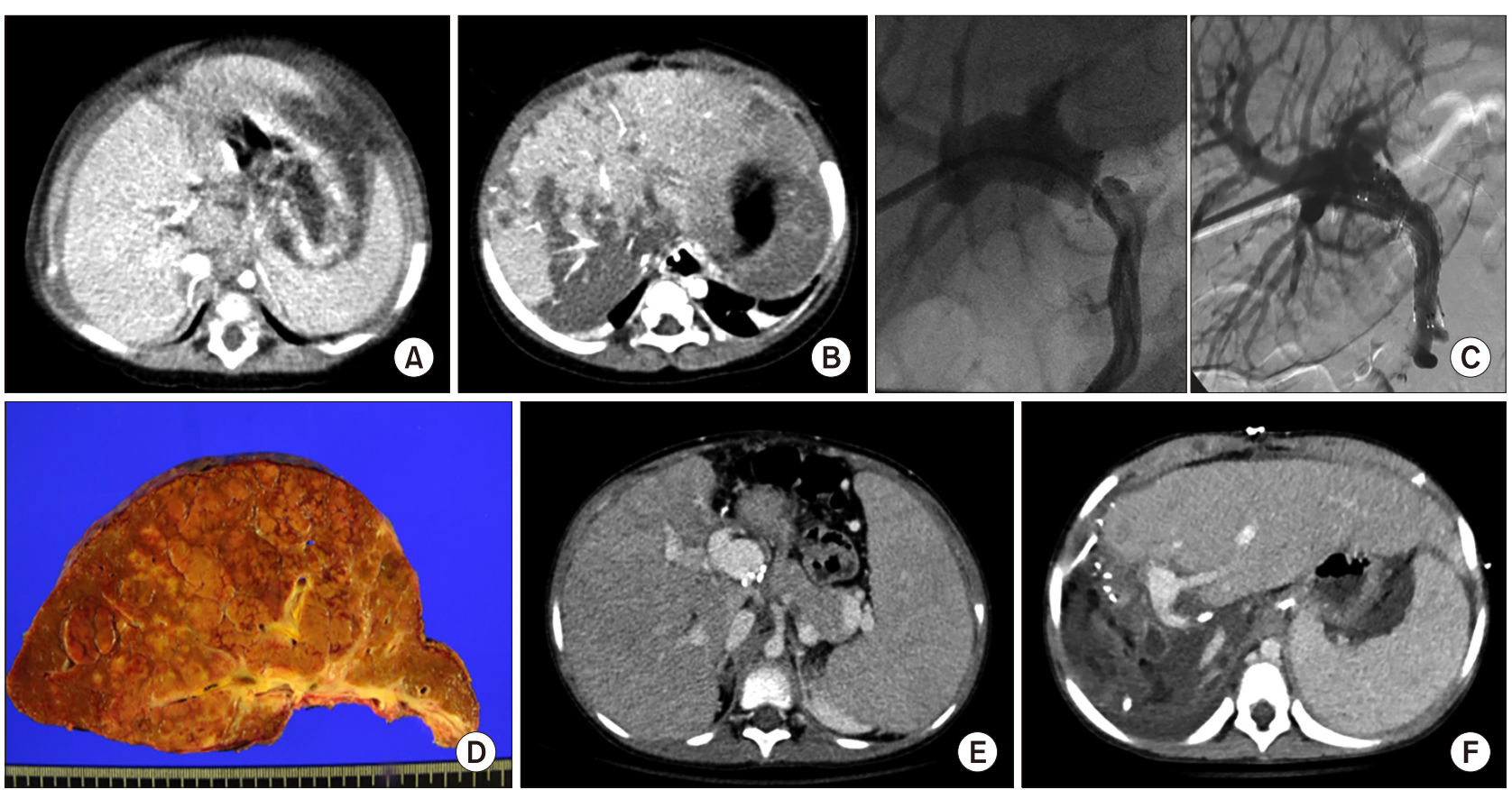

Fig. 3. Clinical sequence of Case No. 1. Computed tomography (CT) images taken preoperation (A) and at day 2 posttransplant (B) showing the sequence of the compression-induced liver infarct. PV anastomotic stenosis (C) was detected and a wall stent was inserted 2 months later. After 6 years, the liver graft failed (D and E) and retransplantation was performed (F). 

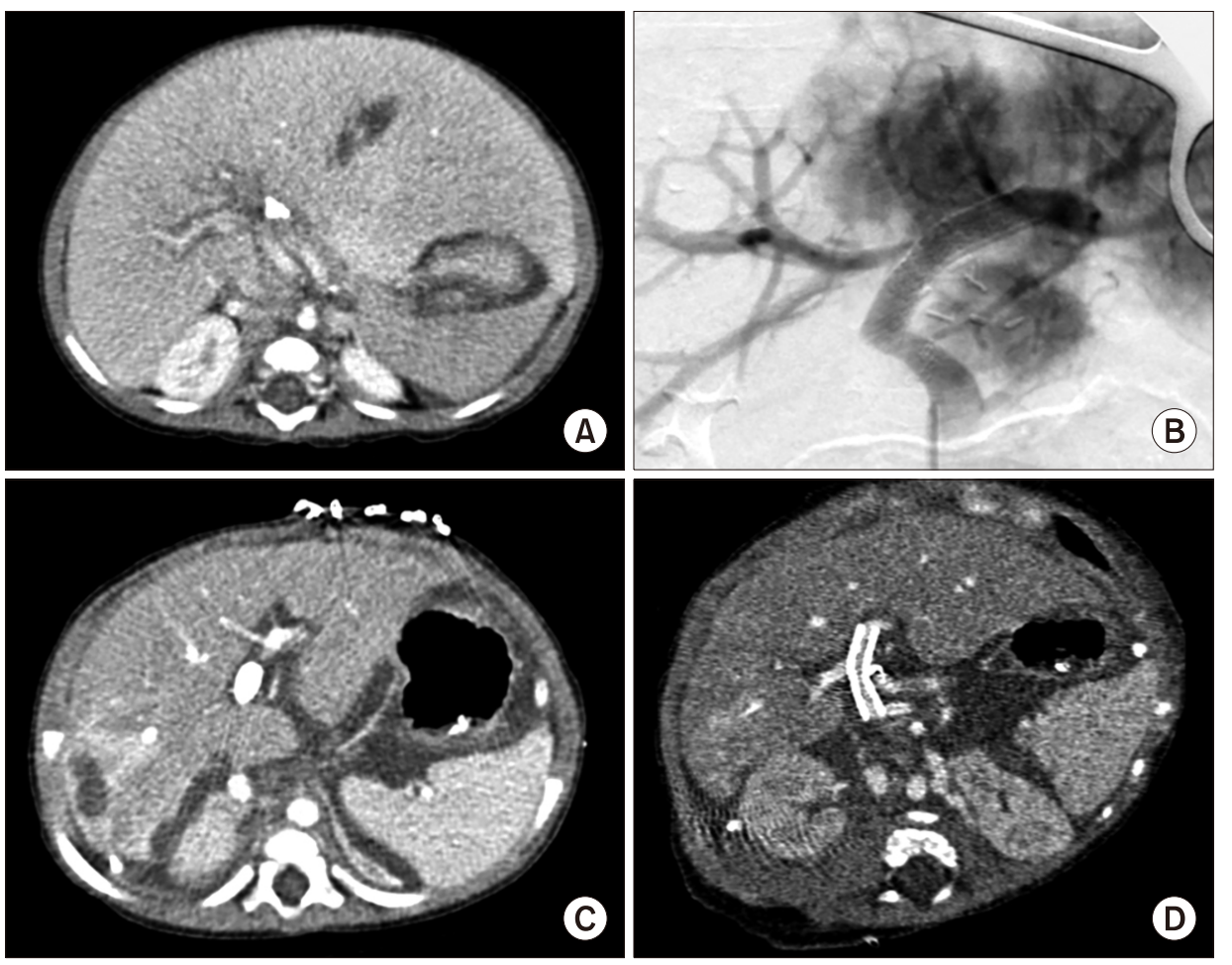

Fig. 4. Clinical sequence of Case No. 2. A preoperative CT scan showed the underdevelopment of the PV (A). Intraoperative PV stenting was performed because of weak PV flow (B). A dynamic CT scan showed reduced perfusion of the liver parenchyma $(\mathrm{C}$ and $\mathrm{D})$.
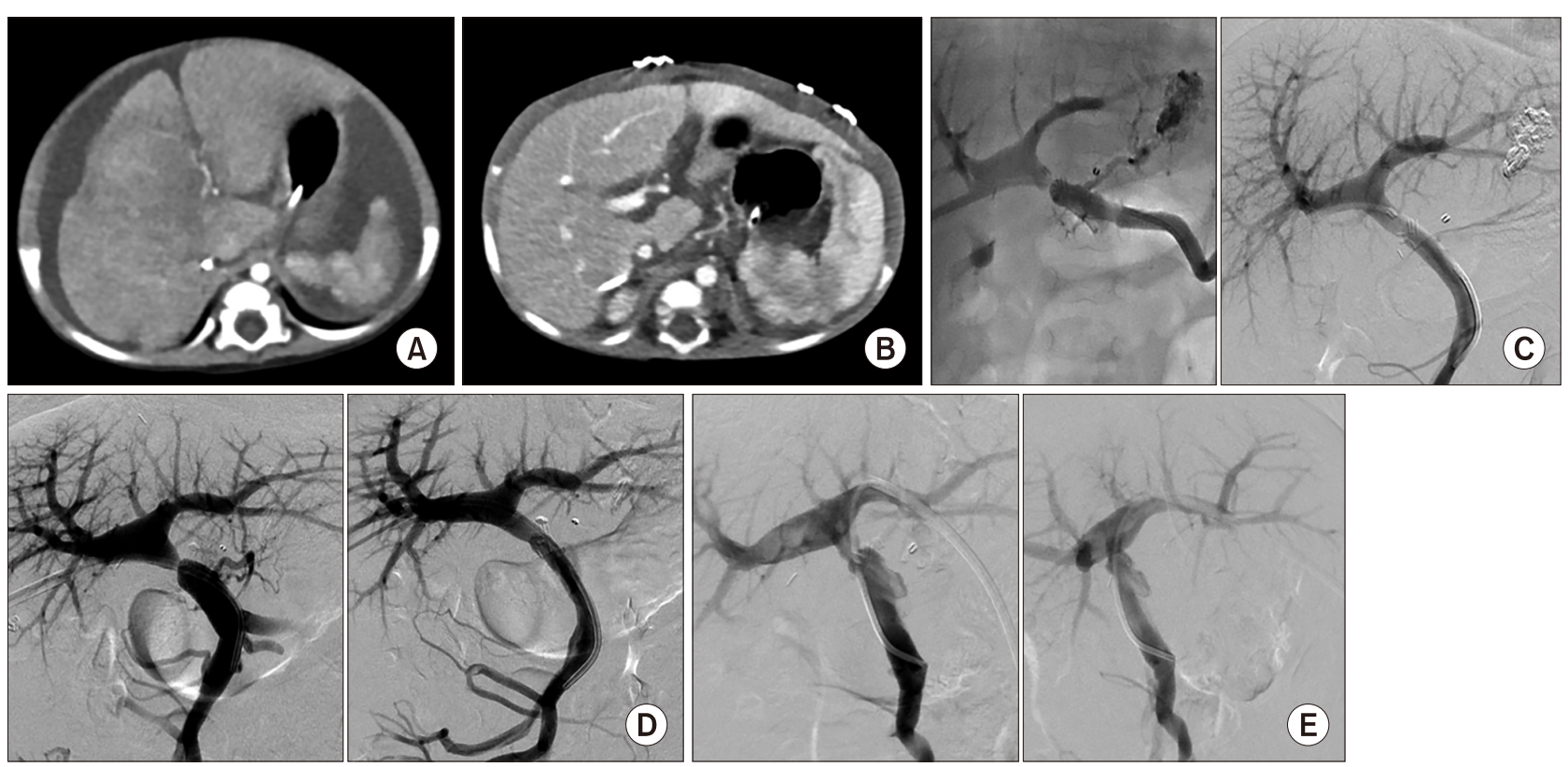

Fig. 5. Clinical sequence of Case No. 3. CT images taken preoperation (A) and at day 7 posttransplant (B) showing the sequence of the PV stenosis. Percutaneous balloon dilatation was repeatedly performed at 2 (C), 6 (D), and 16 months (E).

18-month-old boy. The graft weight was $420 \mathrm{~g}$, so the GRWR was $5.8 \%$. The PV was reconstructed using endto-end anastomosis. Because of abdominal distension resulting from biliary atresia-induced hepatomegaly, we were able to close the abdominal wound at one-stage procedure. The function of the grafted liver recovered uneventfully, but serial imaging studies revealed presence of PV anastomotic stenosis, so PTA with balloon dilatation was performed at posttransplant 2 months. Because of persistent PV anastomotic stenosis, balloon dilatation was repeated at 6 and 16 months after LT. She is currently doing well and is 7 years old (Fig. 5). 
Case No. 4: The recipient was a 10-month-old female baby who weighed $6.0 \mathrm{~kg}$. She was diagnosed with progressive familial intrahepatic cholestasis. The deceased donor was a 12-month-old boy. The graft weight was 245 g, so the GRWR was $4.1 \%$. The PV was reconstructed using above-mentioned side-to-side unification venoplasty (Fig. 6A, B). This was the first case who was benefited from our technical innovation on PV reconstruction. The function of graft liver recovered uneventfully and there was no evidence of PV complications. She is currently do- ing well and is 5 years old. Detailed surgical procedures with donor and recipient video clips were previously presented. $^{9}$

Case No. 5: The recipient was a 16-month-old female baby who weighed $10.1 \mathrm{~kg}$. She had undergone a Kasai operation for biliary atresia. The deceased donor was a 17-month-old boy. The graft weight was $305 \mathrm{~g}$, so the GRWR was $3.0 \%$. The IVC was absent, so the graft IVC was directly anastomosed to the suprahepatic vein stump.
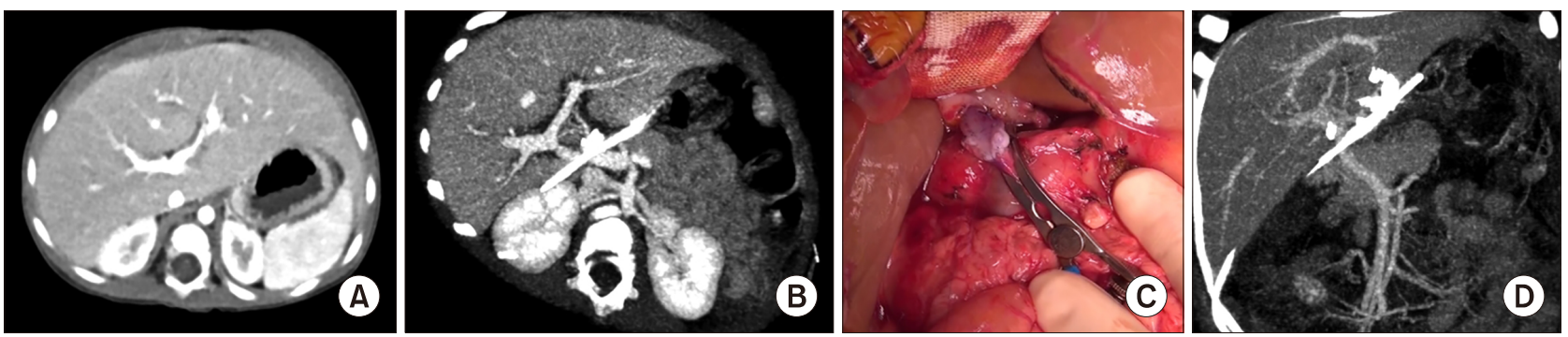

Fig. 6. Imaging findings of $\mathrm{PV}$ reconstruction using the side-to-side unification technique. A comparison of $\mathrm{CT}$ images taken preoperation (A) and at day 7 posttransplant (B) showed no evidence of PV complication in Case No. 4. Intraoperative imaging showed the completed PV reconstruction prior to portal reperfusion (C) in Case No. 5, which resulted in smooth streamlined $\mathrm{PV}$ reconstruction as assessed by day $7 \mathrm{CT}$ angiography (D).
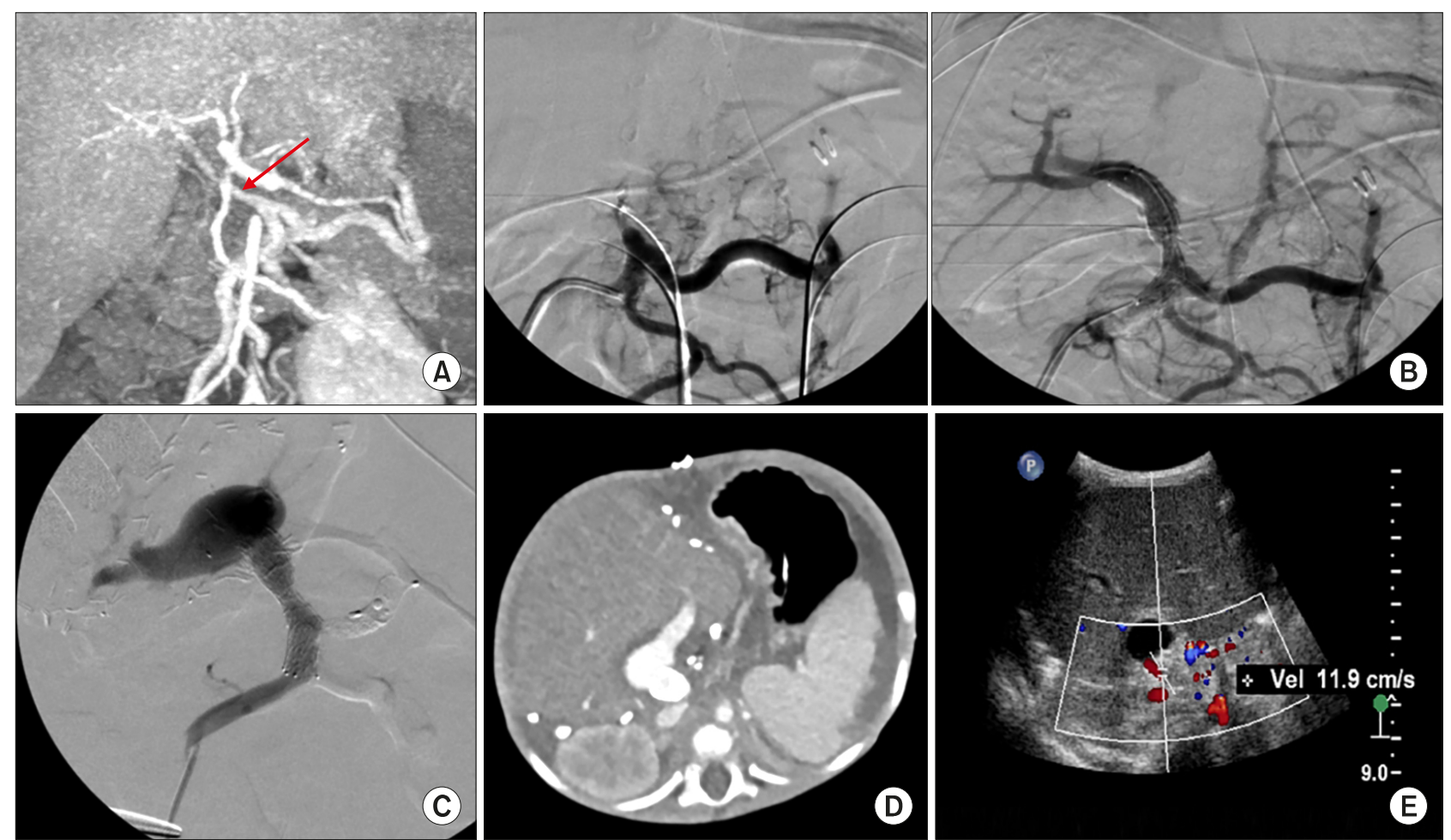

Fig. 7. Clinical sequence of Case No. 6. Preoperative CT angiography (A) revealed marked hypoplasia of the PV (arrow). PV stenting was performed at day 1 because of PV occlusion (B). A direct portogram was also performed during retransplantation, in which potential collateral veins were embolized with multiple coils (C). The liver perfusion status of this patient was poor after retransplantation on day 14, as revealed by CT (D) and Doppler ultrasonography (E). 

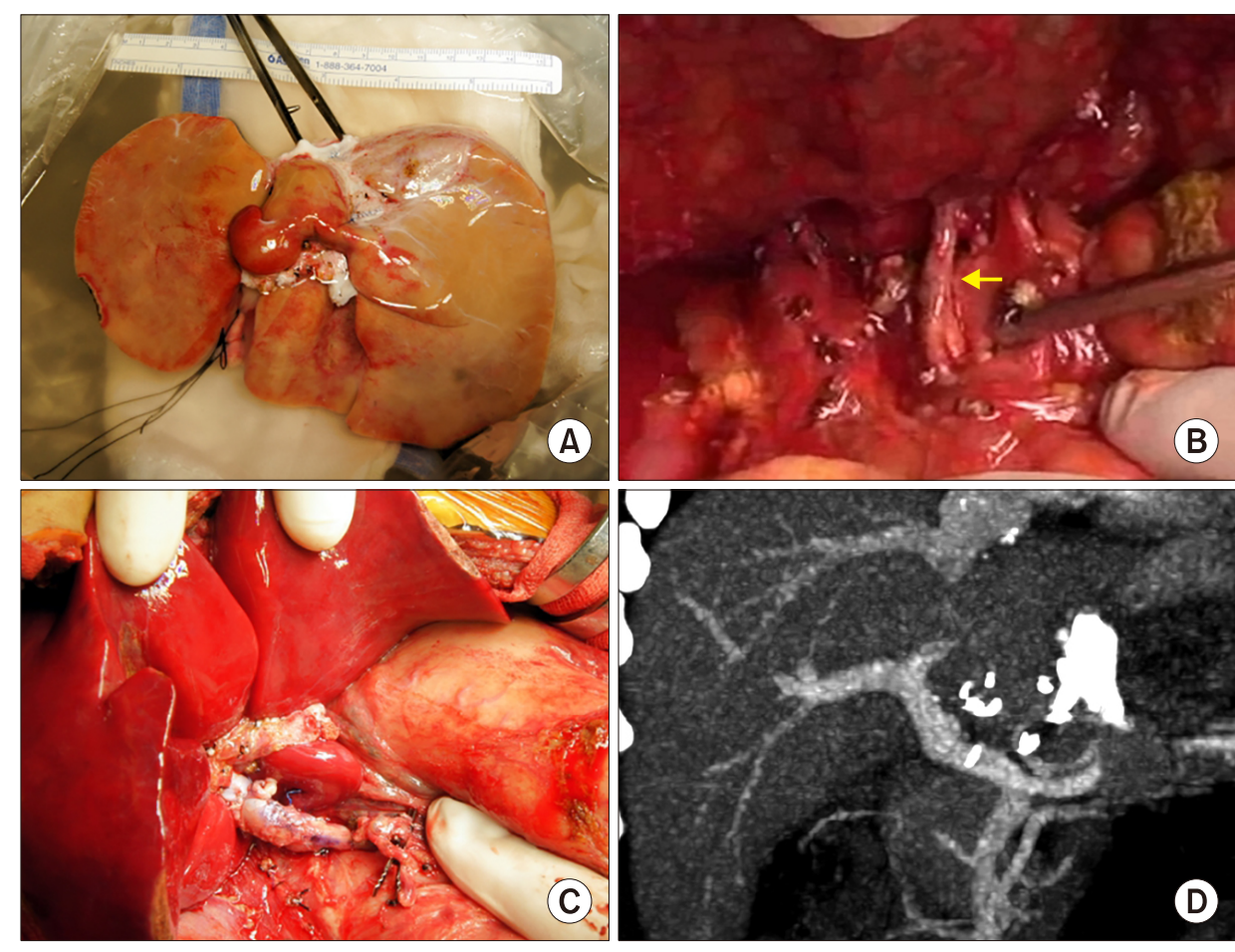

Fig. 8. Imaging findings of PV reconstruction using the side-toside unification technique in Case No. 7. The ventral surface of the whole liver graft was visible with closure of the inferior stump of the vena cava (A). The recipient PV was hypolastic (arrow) (B). Redundant PV reconstruction with side-to-side unification technique was shown to avoid compression by the caudate lobe (C). Dynamic CT portography taken at 1 year showed normal configuration of the PV anastomosis.
The PV was reconstructed using side-to-side unification venoplasty (Fig. 6C, D). The function of the graft liver recovered uneventfully. There was no evidence of PV complications. She is currently doing well and is 6 years old.

Case No. 6: The recipient was a 7-month-old female baby who weighed $5.2 \mathrm{~kg}$. She had undergone Kasai operation for biliary atresia. The deceased donor was 6 months old. The graft weight was $140 \mathrm{~g}$, so the GRWR was $2.7 \%$. The PV was seriously underdeveloped, so a small patch from the donor IVC was attached to the donor PV and a modified form of unification venoplasty was performed. Imaging studies revealed the absence of intrahepatic PV flow at day 1 . Thus, PV stenting was carried out after laparotomy, but only faint PV flow could be observed. She underwent retransplantation with a left lateral segment graft from her mother 7 days later. To increase PV flow, the potential collateral veins were embolized with multiple coils. After retransplantation, her PV flow remained very weak. Her liver function did not recover and ultimately she passed away 37 days after the first LT (Fig. 7).

Case No. 7: The recipient was a 10-month-old female baby who weighed $8.8 \mathrm{~kg}$. She had undergone a Kasai operation for biliary atresia. The deceased donor was a 10-month-old boy. The graft weight was $525 \mathrm{~g}$, so the GRWR was $6.0 \%$. Because the graft liver was much larger than the native liver, we designed the length of the extrahepatic PV more redundant than the precedent cases to avoid extrinsic compression by the large caudate lobe. The PV was reconstructed using side-to-side unification venoplasty (Fig. 8). The function of the graft liver recovered uneventfully. There was no evidence of PV complications. She is currently doing well and is 25 months old. Detailed surgical procedures with a recipient video clip were previously presented. ${ }^{9}$

\section{DISCUSSION}

For I2I-WLT, the most important factors for success of LT are the graft-recipient size matching and PV reconstruction. It is difficult to determine whether the liver graft is well matched with the infant recipient, but general insights can be learned from high-volume center experiences with pediatric LDLT. As guidelines, Sakamoto et al. ${ }^{10}$ proposed a GRWR $<4 \%$ and the ratio of graft liver thickness to the anterior-posterior diameter of the recipient abdomen $<1.0$. $^{11}$ 
For PV reconstruction in I2I-WLT, infant recipients with biliary atresia often exhibit overt PV hypoplasia and underdevelopment of the splanchnic blood flow system, so secure PV reconstruction is a major matter of concern. $^{3,5,12,13}$ Especially for biliary atresia in infants with growth retardation, such as a body weight $5.2 \mathrm{~kg}$ when 7 months old in our case 6 , the PV can be exceptionally small and poorly developed. We previously developed a refined technique for PV reconstruction to deal with PV hypoplasia, which generated a tadpole-shaped PV anastomosis between the femoral vein allograft and recipient SMV-SV confluence. ${ }^{3}$ We have not experienced a case of PV complication after adopting this technique yet in more than 100 cases; therefore, we believe that this technique is effective for pediatric LDLT or split LT. However, it cannot be applied to I2I-WLT because the graft PV is also very small.

After experiencing PV complications in each of the first 3 cases of I2I-WLT, we began to develop a new surgical technique that would be suitable for I2I-WLT, which we termed the side-to-side unification technique. At the recipient-side SMV-SV confluence, this technique is very similar to that of the tadpole-shaped PV anastomosis procedure described above. At the graft-side hilar PV, it is also similar to the use of a conventional patch venoplasty to enlarge the PV diameter. We could attest to its effectiveness and feasibility based on both computational simulation analysis and actual physical model using flexible heat-shrinkable polyolefin tubes. Critically, our side-to-side unification technique was successfully applied to the three cases (Cases No. 4, 5 and 7), which confirmed its feasibility in I2I-WLT.

However, our side-to-side unification technique was not adequately applicable to the Case No. 6 because the PVs of both the donor and recipient were very small. Therefore, we instead performed an additional patch venoplasty. However, blood outflow from the SMV-SV confluence area was too weak to maintain the luminal patency of the reconstructed PV. Considering that the amount of PV flow was too small after PV stenting and retransplant LDLT, we think that this infant was not suitable for any type of LT, and that LT operation should be performed only after allowing for additional growth to occur. In the Case No. 6 , we would regrettably suggest that the retransplant LDLT should not have been performed because of the very high probability of futile transplantation. Special attention should be paid to the infant patients who exhibit severe growth retardation and very poor development of splanchnic system.

Follow-up imaging studies revealed that the shape of the PV after application of side-to-side unification technique had a wide patch-expansion effect at both the SMV-SV and hilar PV confluences. This expansion effect made the shape of the reconstructed PV smooth and streamlined, which is well matched with the hemodynamic principles. After confirming its effectiveness, we also applied this technique to PV reconstruction of pediatric recipients who were older than 12 months of age.

For infant LT recipients, PV stenting should be avoided because it can cause late-onset portal insufficiency that leads to inevitable need for retransplantation. Secure PV reconstruction should be a high priority so that PV stenting can be avoided, which is quite different from adult LT cases because PV stenting in infants cannot be sufficiently enlarged, although there is some enlargement of the PV stent. ${ }^{14,15}$ Finally, PV stenting induces overt PV stenosis when the infant recipients grow up. Indeed, the long-term outcome of percutaneous transhepatic balloon angioplasty is often reported to be favorable in cases of pediatric LDLT. $^{16}$

In conclusion, we present a side-to-side unification technique for PV reconstruction that is applicable to I2I-WLT. Although this technique was successfully applied to only three cases yet, the excellent outcomes of these patients support its technical feasibility and high effectiveness. We propose that this technique may represent a useful surgical option for PV reconstruction in pediatric LT.

\section{CONFLICT OF INTEREST}

No author has any conflict of interest.

\section{ORCID}

Jung-Man Namgoong:

https://orcid.org/0000-0002-9237-7440

Shin Hwang: https://orcid.org/0000-0002-9045-2531

Chul-Soo Ahn: https://orcid.org/0000-0002-3844-3646

Kyoung-Mo Kim: https://orcid.org/0000-0001-7896-6751

Seok-Hee Oh: https://orcid.org/0000-0002-9672-8877 
Dae-Yeon Kim: https://orcid.org/0000-0001-6130-1796

Tae-Yong Ha: https://orcid.org/0000-0001-9932-0212

Gi-Won Song: https://orcid.org/0000-0002-4235-0434

Dong-Hwan Jung: https://orcid.org/0000-0001-5984-023X

Gil-Chun Park: https://orcid.org/0000-0003-1631-3258

\section{AUTHOR CONTRIBUTIONS}

Conceptualization: SH. Data curation: CSA, DYK, TYH, GWS, DHJ, GCP. Metho dology: KMK, SHO. Visualization: SH. Writing - original draft: JMN, SH. Writing - review \& editing: SH.

\section{REFERENCES}

1. Moon DB, Lee SG, Hwang S, Kim KH, Ahn CS, Ha TY, et al. Toward more than 400 liver transplantations a year at a single center. Transplant Proc 2013;45:1937-1941.

2. Oh SH, Kim KM, Kim DY, Song SM, Kim T, Hwang S, et al. Clinical experience of more than 200 cases of pediatric liver transplantation at a single center: improved patient survival. Transplant Proc 2012;44:484-486.

3. Hwang S, Kim DY, Ahn CS, Moon DB, Kim KM, Park GC, et al. Computational simulation-based vessel interposition reconstruction technique for portal vein hypoplasia in pediatric liver transplantation. Transplant Proc 2013;45:255-258.

4. Mitchell A, John PR, Mayer DA, Mirza DF, Buckels JA, De Ville De Goyet J. Improved technique of portal vein reconstruction in pediatric liver transplant recipients with portal vein hypoplasia. Transplantation 2002;73:1244-1247.

5. Takahashi Y, Nishimoto Y, Matsuura T, Hayashida M, Tajiri T, Soejima Y, et al. Surgical complications after living donor liver transplantation in patients with biliary atresia: a relatively high incidence of portal vein complications. Pediatr Surg Int 2009;25:745-751.
6. Ueda M, Egawa H, Ogawa K, Uryuhara K, Fujimoto Y, Kasahara M, et al. Portal vein complications in the long-term course after pediatric living donor liver transplantation. Transplant Proc 2005;37:1138-1140.

7. Gurusamy KS, Pamecha V, Davidson BR. Piggy-back graft for liver transplantation. Cochrane Database Syst Rev 2011;(1): CD008258.

8. Jovine E, Mazziotti A, Grazi GL, Ercolani G, Masetti M, Morganti M, et al. Piggy-back versus conventional technique in liver transplantation: report of a randomized trial. Transpl Int 1997; 10:109-112.

9. Namgoong JM, Hwang S, Ahn CS, Jung DH, Park GC. Side-to-side portal vein reconstruction for infant-to-infant deceased donor whole liver transplantation: report of 2 cases with video. Ann Hepatobiliary Pancreat Surg 2020;24:301-304.

10. Sakamoto S, Kanazawa H, Shigeta T, Uchida H, Sasaki K, Hamano I, et al. Technical considerations of living donor hepatectomy of segment 2 grafts for infants. Surgery 2014;156:12321237.

11. Kasahara M, Sakamoto S, Umeshita K, Uemoto S. Effect of graft size matching on pediatric living-donor liver transplantation in Japan. Exp Clin Transplant 2014;12 Suppl 1:1-4.

12. Kasahara M, Umeshita K, Sakamoto S, Fukuda A, Furukawa H, Uemoto S. Liver transplantation for biliary atresia: a systematic review. Pediatr Surg Int 2017;33:1289-1295.

13. Gu LH, Fang H, Li FH, Zhang SJ, Han LZ, Li QG. Preoperative hepatic hemodynamics in the prediction of early portal vein thrombosis after liver transplantation in pediatric patients with biliary atresia. Hepatobiliary Pancreat Dis Int 2015;14:380-385.

14. Yeh YT, Chen CY, Tseng HS, Wang HK, Tsai HL, Lin NC, et al. Enlarging vascular stents after pediatric liver transplantation. J Pediatr Surg 2017;52:1934-1939.

15. Ko GY, Sung KB, Lee S, Yoon HK, Kim KR, Kim KM, et al. Stent placement for the treatment of portal vein stenosis or occlusion in pediatric liver transplant recipients. J Vasc Interv Radiol 2007;18:1215-1221.

16. Yabuta M, Shibata $T$, Shibata $T$, Shinozuka $K$, Isoda $H$, Okamoto $\mathrm{S}$, et al. Long-term outcome of percutaneous transhepatic balloon angioplasty for portal vein stenosis after pediatric living donor liver transplantation: a single institute's experience. J Vasc Interv Radiol 2014;25:1406-1412. 